\title{
DILEMAS DO TRANSPORTE URBANO SUSTANTÁVEL NO BRASIL
}

Camilo Michalka Jr. ${ }^{1}$

Regina Malaguti ${ }^{2}$

RESUMO: Pela observação do transporte urbano pode-se constatar a maneira como a cidade foi e está sendo construída e é objeto da análise do presente trabalho. Se ela é uma geradora de problemas, sua construção se dá de forma cartesiana, considerando cada elemento que compõe a cidade isoladamente. Se ela é projetada e construída com uma visão de seu todo, de maneira sistêmica, o processo se dá evitando-se problemas. $O$ presente trabalho aborda o transporte urbano, seu planejamento e a integração de diferentes modais. Ele inclui o transporte público e o privado. Dentro desse contexto a bicicleta é analisada também um modal de transporte urbano e sua interação com os demais. É também feita uma análise de como o transporte urbano pode favorecer a integração social ou incentivar sua segregação. Verifica-se a necessidade de que as pequenas cidades mudem a forma de planejamento para deixar de copiar os erros

1 Engenheiro Civil, Mestre em Engenharia Civil pela COPPE/ UFRJ, Doktor Ingenieur pela Universität Stuttgart (Alemanha) e bolsista de Pós-doutorado na Alemanha pelo CNPQ, Programa Ciências sem Fronteiras. É professor associado da Escola Politécnica da Universidade Federal do Rio de Janeiro (Poli/UFRJ), membro efetivo do Programa de Mestrado Profissional em Engenharia Urbana (PEU/Poli/UFRJ) e coordenador do Laboratório de Estudos Estratégicos e Ambientais (www.leeamb.poli.ufrj.br). E-mail: michalka@poli.ufrj.br .

2 Bióloga, Especialista em Engenharia Urbana e mestranda em Engenharia Urbana no Programa de Enganhraria Urbana da Escola Politécnica da Universidade Federal do Rio de Janeiro (PEU/Poli/UFRJ). E-mail: regina.malaguti@poli.ufri.br. 
cometidos por grande parte das grandes cidades brasileiras, que levaram-nas ao estado de caos urbano presente. Partindo-se então da visão sistêmica do planejamento do transporte urbano pode-se também verificar sua relação com setores problemáticos como os de saúde e educação públicas.

Palavras chave: Transporte urbano. Transporte público. Transporte particular.

\section{INTRODUÇÃO}

A cidade, se planejada adequadamente, traz benefícios aos seus habitantes. $O$ aglomerado urbano permite que os serviços públicos possam ser mais eficientes. Para tal, o adensamento populacional exige que a infraestrutura esteja presente. Esta pode ser, para fins organizacionais, divida em infraestrutura técnica e social. A primeira aborda questões como abastecimento d'água, saneamento, transporte público, rede viária etc., enquanto que a segunda aborda a rede de educação, saúde, laser etc. É fácil de perceber que elas são interdependentes.

O presente trabalho faz uma análise das cidades brasileira partindo do transporte urbano. Quanto maior é o adensamento de uma cidade maior se torna a importância da sua rede de transporte. Ela necessita de uma hieraquização e integração dos meios de tranporte, ou seja, dos seus modais, que inclui tanto o público quanto o privado. Nesse contexto, a biciclelta ganha cada vez mais importância em países desenvolvidos, como nos países da Europa do norte. No Brasil ela tem sido desconsiderada no planejamento do transporte urbano. Quando muito, é considerada só em uma de suas funções, que é a de laser.

\section{O TRANSPORTE URBANO}


A maior demanda pelo transporte urbano é no percurso de casa ao trabalho ou à escola e o seu retorno.

O transporte de maior capacidade é aquele sobre trilhos, que inclui metrô e trem. Ainda sobre trilho, mas com menor capacidade está o "bonde", hoje denominado VLT (veículo leve sobre trilhos), nome fruto da vontade de ser moderno, da ideia de implantar o novo. Olhando-se países que não eliminaram o bonde como fez, por exemplo, a cidade do Rio de Janeiro, verifica-se que estes foram se tornando mais modernos, mais confortáveis e mais eficientes, com uma rede viária bem dimensionada, até chegar ao que hoje é denominado no Brasil por VLT.

Um fator para a eficiência do transporte público é a área de abrangência. A distância que o indivíduo está disposto a andar para ter acesso ao transporte público é de até $1 \mathrm{~km}$ (DNIT, 2010, p. 94) Para distâncias maiores irá procurar usar outros meios de transporte. Aqui é de grande eficiência o uso da bicicleta. Entretanto é necessário dispor de locais para estaciona-las nos pontos de conexão com o transporte público. $\mathrm{O}$ uso do automóvel para esse fim, no lugar da bicicleta, exige maiores áreas de estacionamento.

Um transporte público urbano eficiente necessita ter duas características: ser confortável e ter uma acessibilidade rápida e fácil. Faz parte da acessibilidade a mudança de veículo / modal no trajeto origem - destino.

Acessibilidade começa por entrar no veículo. A boa acessibilidade tem a plataforma de acesso no mesmo nível dos veículos, tolerando-se pequenos desníveis.

Os ônibus que circulam pela rede viária comum exigem normalmente o pagamento da passagem ou a colocação de cartões para leitura dentro do veículo, com a necessidade, em seguida, de se transpor uma roleta. Em pontos de ônibus com muita demanda, o volume de pessoas para entrar no veículo é grande, fazendo com que este fique parado vários minutos. Ao longo do percurso, isso faz com que haja um aumento desnecessário e considerável no tempo de viagem.

Com relação à acessibilidade, as roletas dos ônibus, em geral, são barreiras para pessoas idosas, mulheres grávidas, pessoas com crianças pequenas assim como para aquelas que possuam necessidades especiais etc. A solução para cadeiras de rodas, por meio de um elevador de acesso, exige mais tempo o que aumenta a viagem. 
Com relação ao conforto, grande parte das carrocerias dos ônibus ainda é montada em chassis de caminhão, o que exige que o passageiro suba três degraus altos. Dentro desses ônibus o conforto deixa a desejar, particularmente para percursos longos.

A forma de condução do ônibus é outro fator de desconforto. Mudanças de direção bruscas, freadas e acelerações fortes, contribuem para tal. Nesse ponto é bom salientar as condições de trabalho dos motoristas, que dirigem muitas vezes com o calor do motor ao seu lado e competindo com outros veículos pelo espaço nas ruas. Tudo isso leva a uma carga de tensão muito grande. Isso se torna patente também quando eles têm que lidar com passageiros grosseiros ou motoristas particulares imprudentes.

A falta de integração entre as linhas de transporte público faz com que haja um número excessivo de ônibus nas ruas. Há pontos finais de onde partem linhas nas mais diversas direções, com longo percurso comum, onde trafegam com pequeno número de passageiros. Com uma integração com mudança rápida de veículo, reduz-se número de veículos e aumenta-se sua velocidade média, reduzindo o tempo de viagem. Reduz-se assim também poluição do meio ambiente.

Os ônibus que circulam juntamente com os outros veículos estão sujeitos aos engarrafamentos comuns e diários na cidade. Os passageiros têm que suportar o longo tempo no desconforto, fato que se agrava quando o passageiro faz esse percurso em pé.

Torna-se então urgente a criação de faixas exclusivas para ônibus, permitindo que haja fluidez no seu fluxo.

Some-se a possibilidade do uso de diferentes modais de forma integrada e os deslocamentos serão mais confortáveis e rápidos.

Um ponto importante para o transporte público é haver um plano de horários. $O$ cidadão estará mais inclinado a usar o transporte se ele souber a que horas passa o ônibus, trem ou metrô. Isso é particularmente crítico nos fins de semana, quando o número de veículos diminui. Mas como fazer esse planejamento de horários com o transporte público circulando junto com os veículos particulares, ficando sujeito aos engarrafamentos? 


\subsection{A BICICLETA, A LEGISLAÇÃO E AS NORMAS TÉCNICAS}

Completando o modal urbano, um veículo que pode ser fundamental é a bicicleta. Como transporte urbano, ela tem várias características positivas. Até uma certa distância ela pode ser um meio extremamente eficiente como único transporte. Quando as distâncias são maiores ela pode ser utilizada combinada a outros modais.

Para o incentivo ao uso da bicicleta é fundamental que ela seja considerada no traçado das vias urbanas. Prover estacionamento e respeitar suas características de deslocamento, diferentes dos veículos automotores e, particularmente, dos pedestres.

A movimentação de veículos, pessoas e animais é regida, em todo o território nacional, pelo Código de Trânsito Brasileiro - CTB, Lei nº 9.503, 23 de Setembro de 1997.

Um dos objetivos do Código é a padronização da sinalização para que ela seja a mesma em todo o território nacional, evitando assim, dificuldades na interpretação, que pode conduzir a situações de risco e acidentes. No CTB, no Capítulo II, seção II o Art. 12, define:

\section{Art. 12. Compete ao CONTRAN:}

$[\ldots]$

XI- aprovar, complementar ou alterar os dispositivos de sinalização e os dispositivos e equipamentos de trânsito; (BRASIL, 1997)

Fica claro que só o Conselho Nacional de Trânsito - CONTRAN é responsável por definir a sinalização de trânsito. Uma equipe de técnicos elaborou então o Manual Brasileiro de Sinalização de Trânsito, composto de vários volumes (Malaguti, 2012). Dentre eles, três têm especial importância. São os seguintes volumes:

- Volume I - Sinalização Vertical de Regulamentação, Resolução 180/05 (BRASIL, 2007a)

- Volume II - Sinalização Vertical de Advertência, Resolução 243/07 (BRASIL, 2007b)

- Volume IV - Sinalização Horizontal, Resolução 236/07 (BRASIL, 2007c)

Em todos eles constam como objetivos: a Legalidade, a Suficiência, a Padronização, a Clareza, a Precisão e Confiabilidade, a Visibilidade e legibilidade e a Manutenção e Conservação - (BRASIL, 2007a p.22); (BRASIL, 2007b, p.10); (BRASIL, 2007c, p. 4). 
Por outro lado, o CTB em seu Art. 1 diz: "O trânsito de qualquer natureza nas vias terrestres do território nacional, abertas à circulação, rege-se por este Código."

O CTB define trânsito da seguinte forma:

$\S 1^{\circ}$ Considera-se trânsito a utilização das vias por pessoas, veículos e animais, isolados ou em grupos, conduzidos ou não, para fins de circulação, parada, estacionamento e operação de carga ou descarga.

[...]

Art. $3^{\circ}$ As disposições deste Código são aplicáveis a qualquer veículo, bem como aos proprietários, condutores dos veículos nacionais ou estrangeiros e às pessoas nele expressamente mencionadas. (BRASIL, 1997)

Apesar do CTB dizer que o CONTRAN tem a prerrogativa de definir a sinalização rodoviária, cidades como Rio de Janeiro e Florianópolis, criaram sua própria sinalização cicloviária (BRASIL, 2005; BRASIL, 2002) em desrespeito frontal à legislação superior. Um exemplo disso está na figura 1 (Malaguti 2012).

a)

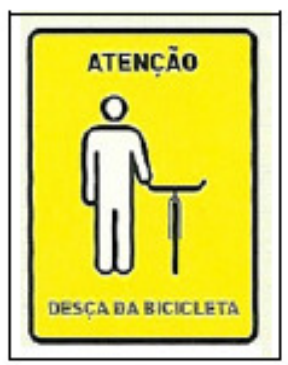

c)

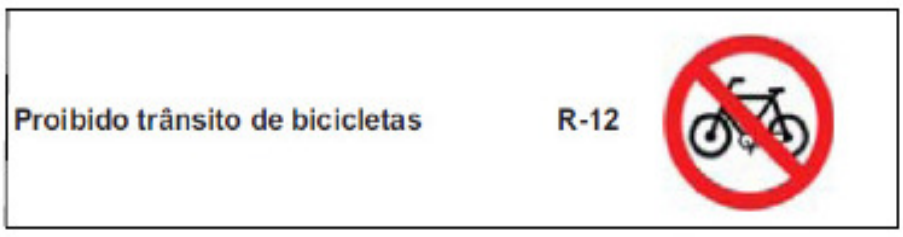

b)

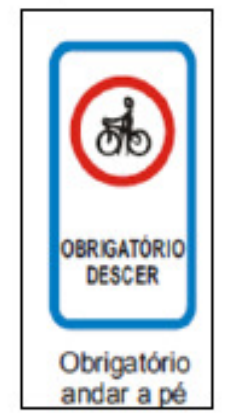

andar a pé 列 
Por outro lado, cuidados especiais têm que ser adotados em áreas mais adensadas devido aos conflitos que ocorrem pelas características e comportamento de pedestres e ciclistas.

O Manual de Projeto Geométrico de Travessias Urbanas - DNIT (2010), elaborado por profissionais de trânsito, é uma referência obrigatória para os técnicos que são responsáveis, entre outras coisas, por planejar a circulação de bicicletas em áreas urbanas adensadas (MICHALKA; MALAGUTI, 2012). Recomendações que são mais pertinentes ao presente trabalho são apresentadas a seguir.

O item 4 - Critérios e Controles de Projeto apresenta as características da movimentação de pedestres.

Segundo a AASHTO (apud DNIT, 2010), as velocidades dos pedestres podem variar de 0,8 a $1,8 \mathrm{~m} / \mathrm{s}$. São influenciadas pelas características físicas da via, pela localização em relação à quadra, por declives e aclives, temperatura ambiente, hora do dia, objetivo da viagem e idade.

Conforme a idade, a capacidade de discernimento de espaço, distâncias,

\begin{tabular}{|c|c|}
\hline 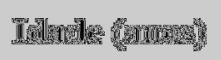 & 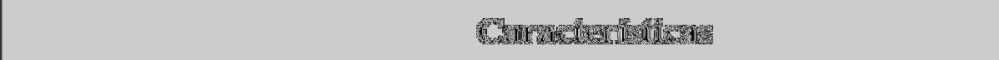 \\
\hline $0-4$ & 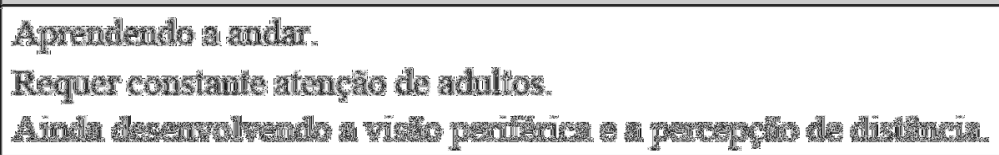 \\
\hline $5-5$ & 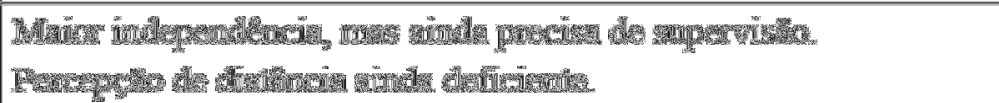 \\
\hline-15 & 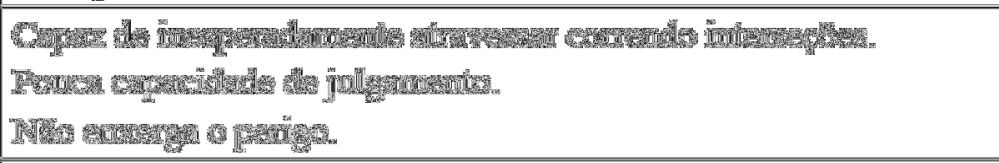 \\
\hline In & 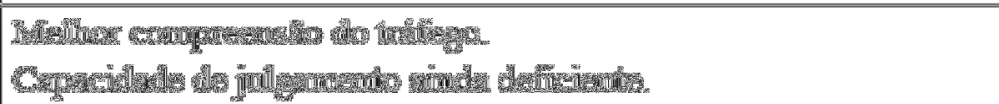 \\
\hline$n g-40$ & 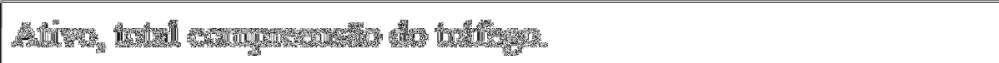 \\
\hline $41-5$ & 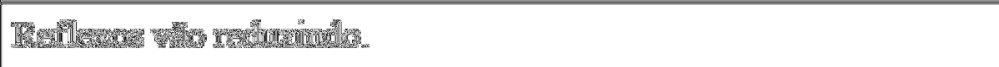 \\
\hline S. & 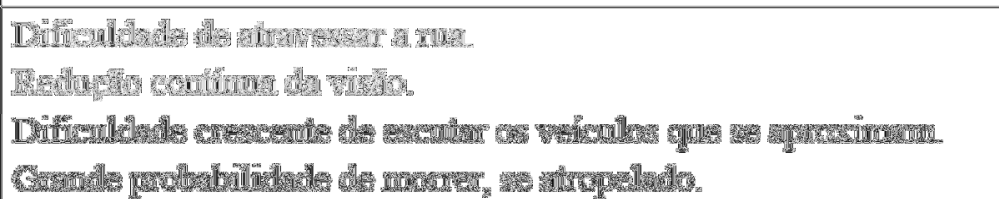 \\
\hline
\end{tabular}

velocidades, pelo pedestre sobre alterações. A figura 2 apresenta essas características. 
Figura 2 - Quadro das características comuns a pedestres por grupo de idade. Fonte Pedestrian Facilities Guidebook into Washington's Trasnportation System, Washington State Department of Trasnportation, 1977 apud DNIT, 2010, p. 95.

Outra característica é o nível de serviço e seus fluxos, quando são definidas as grandezas de densidade, fluxo e velocidade dos pedestres, conforme está no Manual do DNIT (DNIT, 2010, p.86 a 88)

- Nível de Serviço A - Área média por pedestre $\geq 1,2 \mathrm{~m}^{2} / \mathrm{p}$. Circulação livre dentro da área, sem conflito entre pedestres.

- Nível de Serviço B - Área média por pedestre: 0,9-1,2 $\mathrm{m}^{2} / \mathrm{p}$. Circulação parcialmente restrita, sem conflito entre pedestres.

- Nível de Serviço C - Área média por pedestre 0,6-0,9 m²/p. Circulação mais restrita, com prováveis conflitos.

- Nível de Serviço D - Área média por pedestre 0,3-0,6 m²/p. Circulação severamente restrita. Deslocamento só é possível em grupo. Espera desconfortável.

- Nível de Serviço E - Área média por pedestre 0,2-0,3 $\mathrm{m}^{2} / \mathrm{p}$. Contato físico inevitável. Impossibilidade de circulação. Espera extremamente desconfortável.

- Nível de Serviço F - Área média por pedestre $\leq 0,2 \mathrm{~m}^{2} / \mathrm{p}$. Cresce o potencial para pânico se o volume se tornar excessivo.

Outra característica dos pedestres é que suas ações são menos previsíveis que as dos motoristas. Com frequência desobedecem às leis de trânsito, também porque a cobrança é praticamente inexistente no Brasil. Eles tendem a se deslocar por trajetória de menor distância e mudam rapidamente de direção. Esse comportamento também torna a convivência com ciclistas, em áreas adensadas, sempre uma situação de conflito e potencialmente perigosas.

Os passeios para circulação de pedestres devem ter de 1,20m a 2,40m, podendo ser maiores, devem ter um canteiro entre na borda da via de, no mínimo 0,60m (DNIT, 2010, p.97). Em áreas comerciais, complexos residenciais e pontos geradores de tráfego de pedestres como escolas, justifica-se que o passeio se estenda até à margem da via. Nesse caso, a largura deve ser 0,60m maior do que quando da existência de canteiro. $O$ canteiro é útil também ambientalmente, pois permite que a água da chuva penetre no terreno e, arborizado, dê sombra, contribuindo para evitar a formação de ilhas de calor.

A velocidade da bicicleta atinge, segundo Estudos realizados por Pein (Trail Intersection Design Guidelines - Florida Department of Transportation - 1996, apud DNIT, 2010 p. 113) os seguintes valores: 
- Velocidade em terreno plano:

- Valor mínimo para projeto: $32 \mathrm{~km} / \mathrm{h}$

- Velocidade abaixo da qual $85 \%$ dos ciclistas viaja: $22 \mathrm{~km} / \mathrm{h}$

- Velocidade em descida: $50 \mathrm{~km} / \mathrm{h}$

- Velocidade em subida: $10 \mathrm{~km} / \mathrm{h}$

- Atravessando uma interseção a partir da posição de repouso:

- Velocidade média: $12,7 \mathrm{~km} / \mathrm{h}$

- Velocidade, abaixo da qual, $15 \%$ dos ciclistas viaja: $10,8 \mathrm{~km} / \mathrm{h}$

- Aceleração a partir da posição de repouso:

- Aceleração média: 1,07 m/s2

- Aceleração dos ciclistas mais lentos: $15 \%$ abaixo de 0,74 $\mathrm{m} / \mathrm{s} 2$

- Desaceleração

○ Máxima: $5 \mathrm{~m} / \mathrm{s} 2$

o Típica: 1,2 a $2,5 \mathrm{~m} / \mathrm{s} 2$

Comparando-se os valores de velocidades de pedestres e ciclistas, assim como seus comportamentos, fica patente que, em áreas densamente habitadas, bicicletas e pedestres são de convivência incompatível, por não dizer, impossível. Há uma situação potencial alta de conflito e acidentes. Isso tem que ser considerado se houver o objetivo de incentivar o uso da bicicleta como modal de transporte urbano.

Para que a bicicleta atinja sua velocidade normal, conforme descrito acima, ela exige, em áreas urbanas de ocupação densa, de vias exclusivas. Elas são as ciclovias e ciclofaixas. Estas necessitam também de larguras mínimas. Elas podem ser unidirecionais e bidirecionais. A figura 3 ilustra a largura ocupada pela bicicleta. Verifica-se que largura mínima de uma ciclovia unidirecional é de 1,20m .

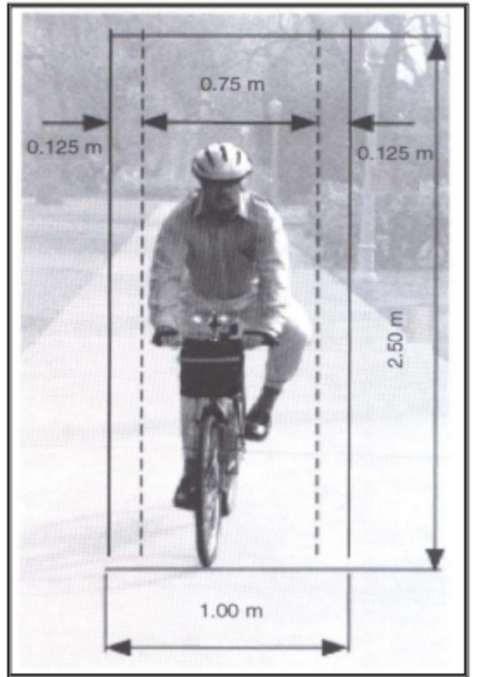

Figura 3 - Espaço necessário para ciclistas. Ref. DNIT, 2012 p. 113. 
É chamada atenção para o fato de que a bicicleta, em baixas velocidades, não têm um movimento retilíneo. Esse movimento torna-se mais retilíneo conforme a velocidade aumenta. Velocidades menores exigem larguras maiores, sendo recomendado então que a largura mínima seja de $1,50 \mathrm{~m}$. No caso de ciclovia bidirecional a largura mínima recomendada é de $2,50 \mathrm{~m}$.

Caso haja a intensão de estimular o uso de bicicletas como modal de transporte urbano, esforços especiais devem ser dedicados para assegurar uma eficiente rede viária provida de faixas próprias, permitindo ao ciclista desenvolver velocidades compatíveis com esse veículo.

Alguns outros pontos devem ser cuidadosamente observados são os seguintes:

- A continuidade da via é muito importante; prover ao ciclista fazer o trajeto sem trechos onde deve circular junto a veículos ou pedestres ou empurrando a bicicleta.

- Deve ser dada ao ciclista condições de manter sua velocidade; alterações de velocidade e direção provocadas por obstáculos na pista desestimulam o uso da bicicleta.

- O projeto deve evitar conflito com pedestres, evitando assim acidentes.

- As grelhas das sarjetas de drenagem devem ser próprias para a travessia de bicicletas.

- Ciclofaixas devem acompanhar a mão da via; vias de mão única só comportam ciclofaixas unidirecionais; em vias de mão dupla de grande movimento, devem ser posicionadas duas ciclofaixas ou ciclovias, uma em cada lado da via, acompanhando o sentido do trânsito.

- O uso cuidadoso, correto e exclusivo da sinalização do CONTRAN, para evitar má interpretação; por exemplo, o símbolo da figura 4 significa que a via é para uso exclusivo de BICICLETAS.

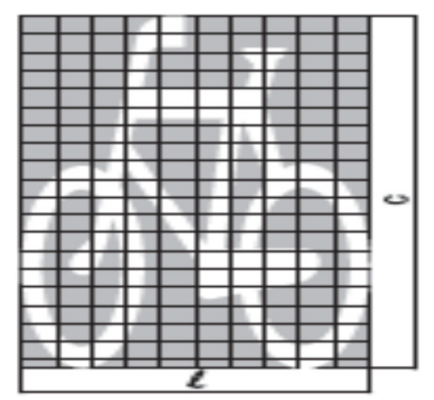


Figura 4 - Definição do Manual de Sinalização Horizontal (BRASIL, 2007c, p. 98): O SIC "Bicicleta" é utilizado para indicar a existência de faixa ou pista exclusiva de ciclistas.

- Leis e regulamentos federais, estaduais e municipais, nessa ordem hierárquica tem que ser respeitadas. Os programas de sistemas de vias para ciclistas devem refletir as leis e regulamentos existentes. Eventuais alterações que se considerem necessárias nas leis e regulamentos existentes devem ser objeto de tratamento junto às autoridades responsáveis pelos mesmos.

- Fundamental observar que nos três volumes do CONTRAN consultados, a palavra deve está sempre grifada pelo autor. Cabe então definir seu significado, para maior compreensão da sua aplicação, que é o de ter obrigação de, conforme consta no Dicionário Aurélio Eletrônico (HOLANDA, 2004). Ou seja, tem o caráter de dever, obrigação, ao contrário de ser sugestão ou opção. (MALAGUTI, 2012, p.26)

\section{O DESAFIO DO ESTÍMULO AO USO DO TRANSPORTE PÚBLICO}

Do que foi acima abordado, qual é o comportamento das pessoas em relação à opção pelo meio de transporte para o deslocamento?

A questão do transporte urbano passa por pontos diversos.

É ponto negativo em boa parte das cidades brasileiras a pequena rede de transporte público de alta capacidade.

O transporte público de média capacidade começa tomar impulso agora, com a construção das faixas exclusivas para o BRT.

Em geral, entretanto, a maior parte das cidades é servida por transporte público de baixa capacidade que são os ônibus. Estes circulam principalmente no trânsito comum.

O transporte público então é, em sua maioria, desconfortável e lento.

Do exposto é fácil constatar que as classes sociais que podem se permitir ter um automóvel em geral não utiliza o transporte público, que fica para uso da grande parte da população que não pode se permitir possuir um. 
O grande desafio das cidades brasileiras é tornar o transporte público atrativo a todas as classes sociais. Para isso, medidas devem ser tomadas visando:

- tempos de viagens previsíveis e controláveis;

- maior velocidade média, com redução de tempos de viagem;

- diminuição da circulação de veículos na cidade.

A diminuição dos veículos circulando pela cidade traz grandes benefícios ao meio ambiente. Mais visíveis são a diminuição da poluição do ar e sonora. Mas outros fatores positivos são alcançados. O menor consumo de óleos lubrificantes e a menor geração de partículas por desgastes dos pneus, como também a redução do aquecimento da cidade pelo funcionamento dos motores dos veículos. Esses são alguns dos benefícios diretos.

A inclusão da bicicleta como modal de transporte diário também beneficia a saúde por levar as pessoas a deixar de ter uma vida sedentária. Estimula a circulação sanguínea, aumenta o tônus muscular, a capacidade respiratória e beneficia a flexibilidade por exercitar as articulações. Tudo isso dá às pessoas mais disposição e saúde.

\subsection{O TRANSPORTE PÚBLICO EM CIDADES PEQUENAS}

Cidades pequenas têm mais facilidade de implantar um sistema de transporte público de qualidade. Com pouco adensamento, podem ser tomadas medidas para a construção de vias exclusivas para ônibus e prever, para o caso de crescimento, a adoção de modais de maior capacidade. Com isso, estimula-se o uso do transporte público.

É comum no Brasil pensar-se em alguma solução quando o problema já existe. Essa é uma postura que necessita ser mudada. É mais barato, mais fácil e mais inteligente evitar problemas. $\mathrm{E}$ as cidades pequenas podem fazer isso.

Aqui cabe um parêntese. As cidades pequenas não têm capacidade para ter uma equipe técnica que englobe todas as áreas presentes nos seu planejamento. Um caminho 
viável e fácil é usar a universidade, principalmente a pública, para dar assessoria na abordagem técnica da cidade.

Torna-se fundamental e urgente que as cidades pequenas deixem de continuar copiando todos os erros das grandes cidades. Isso tem sido quase que regra: quando as cidades brasileiras entram em processo de crescimento, após pouco tempo, já apresentam todos os problemas das grandes cidades, entre eles, o trânsito, a poluição dos cursos d'água, a destruição da flora e fauna pela extinção das áreas verdes entre outros.

\section{CONCLUSÕES}

A cidade traz para a sociedade inúmeros benefícios. Para tal é fundamental um planejamento que a aborde como um todo. Conforme o local ou o caráter de uma intervenção na cidade, ela será sentida mais fortemente em umas áreas do que em outras. Mas sempre estará influenciando toda ela. A soma das consequências de todas as intervenções urbanas ganha grande intensidade na vida da cidade. Por isso é fundamental planejá-la de forma sistêmica.

Da análise feita nesse trabalho, verifica-se que o transporte urbano, particularmente o transporte público tem sido implantado nas cidades brasileiras, em geral, de forma cartesiana.

É fundamental planejar baseado numa análise de demanda, integrando os diferentes modais, desde aqueles de grande capacidade (trem e metrô), passando pelo o de média capacidade (VLT e BRT) até o de pequena capacidade (ônibus e micro-ônibus). Esse planejamento deve prever também o uso do veículo particular e sua integração com o transporte público em áreas menos densas.

A bicicleta pode ser um importante meio de transporte urbano diário para pequenas distâncias. Para ser um modal de transportes é fundamental haver uma rede viária de circulação livre e exclusiva da bicicleta, principalmente em áreas mais adensadas, como foi abordado no item 2.1. Uma rede cicloviária que deixa de seguir a legislação e as 
orientações técnicas torna-se ineficiente e leva a conflitos e acidentes, principalmente desestimulando seu uso como meio de transporte urbano.

O transporte nas cidades brasileiras é, em geral, ruim. Principalmente pela ausência de um planejamento sistêmico. Essa ausência faz com que o transporte público seja de baixa capacidade e circule em conjunto com os demais veículos. Isso tem como consequências:

- tempos de viagem excessivos;

- desconforto, não só pelas características do veículo, com abordado no item 2, mas pelo seu agravamento devido tempo de viagem excessivo;

Com raras exceções, são inexistentes, nas paradas de ônibus, informação sobre quais as linhas que passam por ali e, muito menos, seus percursos. Só os usuários constantes sabem que condução tomar. Turistas ficam totalmente perdidos quando desejam usar o transporte público no Brasil. Outro fator de incentivo ao turismo é a ligação de rodoviárias e aeroportos por meio de transporte sobre trilhos. É desestimulante, por exemplo no Rio de Janeiro, chegar-se ao aeroporto internacional Antonio Carlos Jobim na parte da manhã e ter que passar um longo tempo no engarrafamento diário na Linha Vermelha ou Av. Brasil, ou ter que ainda fazer uso pela linha Amarela.

Outro fator que desestimula, muitas vezes, o uso do transporte público é a ausência de informação da frequência com que o ônibus circula. Isso é mais grave nos fins de semana quando os intervalos são maiores.

Isso faz do automóvel um objetivo. Se for para ficar engarrafado, é preferível um veículo com bons acentos, ar condicionado, com música que pode ser selecionada, inclusive com diversas mídias. Mesmo que isso contribua para o aumento dos engarrafamentos e, com isso, dos tempos de viagem e da sobrecarga ao meio ambiente.

Então, a parcela da população que pode se permitir ter um automóvel, em geral, usa esse veículo. $O$ transporte público fica para os que não podem ter um carro.

Com isso fica caracterizado que a falta de planejamento sistêmico do transporte urbano, particularmente o público, leva também à segregação social. 
A bicicleta pode contribuir positivamente como modal de transporte. Entretanto, a ausência de ciclovias dentro do definido no Código de Trânsito Brasileiro e nas recomendações técnicas cria conflito pela disputa do espaço entre bicicletas, automóveis e, particularmente, pedestres. Isso desestimula o uso da bicicleta como meio transporte urbano.

Um transporte público planejado e integrado, com vias exclusivas e com veículos projetados para esse fim, incentiva o seu uso, levando inclusive à convivência de diferentes classes sociais. O que poderia ser um fator de integração tornou-se em diversas cidades brasileiras, pela ausência de planejamento, um fator de separação social.

Esse é um exemplo da perversidade das grandes cidades que crescem sem desenvolvimento. Crescem sem planejamento sistêmico. Uma colcha de retalhos disforme e desconecta.

As cidades brasileiras passam, em geral, pelo dilema de como resolver a questão de trânsito. A única saída é enfrentar, sem rodeios e sem paliativos, o projeto de transporte público, com ações de curto, médio e longo prazo. Entretanto, é impossível tratar a questão isoladamente. Só haverá transporte público de qualidade se as medidas e os projetos de adensamento urbano o levar em consideração. De que adiante que seja feito um transporte público para uma determinada demanda e aumenta-la em seguida, consequência de um novo adensamento. Nesse caso, como é comum no Brasil, o transporte público voltará a ser insuficiente, não suportando a nova demanda. Isso é o que também acontece com a infraestrutura de saúde e educação. Uma infraestrutura de saúde e educação que deixe de levar em consideração um aumento de adensamento, da mesma forma que com o transporte público, deixa de ser eficiente, caindo sua qualidade e criando conflitos entre a população e os profissionais dessas áreas.

\section{REFERÊNCIAS}


BRASIL. Ministério da Justiça. LEI N.9.503, 23 de Setembro de 1997. Institui o Código de Trânsito Código Brasileiro. Brasília, DF, 1997. Disponível em: <http://www.planalto.gov.br/ccivil_03/Leis/L9503.htm >.

Conselho Nacional de Trânsito. Departamento Nacional de Trânsito. Sinalização Vertical de Regulamentação. 2. ed. Brasília, 2007a. Manual de Sinalização Brasileiro de Sinalização. v.1.220 p.

. Conselho Nacional de Trânsito. Departamento Nacional de Trânsito. Sinalização Vertical de Advertência.2. ed. Brasília, 2007b. Manual Brasileiro de Sinalização. v.2. 218 p.

Conselho Nacional de Trânsito. Departamento Nacional de Trânsito. Sinalização Horizontal. 1 ed. Brasília, 2007c. Manual Brasileiro de Sinalização de Trânsito. v.4. 128 p.

.Departamento Nacional de Infraestrutura de Transportes. Instituto de Pesquisas Rodoviárias. Manual de sinalização rodoviária. -3. ed. - Rio de Janeiro,2010. 412p.

Instituto Pereira Passos. Ciclovias Cariocas. Prefeitura da Cidade do Rio de Janeiro, 2005. $188 \mathrm{p}$.

Instituto de Planejamento Urbano de Florianópolis. Pedalando em Florianópolis Manual do Ciclista. Florianópolis, 2002. 77 p.

MALAGUTI, R.: Sinalização Cicloviária Federal Brasileira e Sua Aplicação. 2012, 71p. Monografia (Curso de Especialização em Engenharia Urbana). Universidade Federal do Rio de Janeiro, 2012.

MICHALKA Jr, C.; MALAGUTI, R.: As Denominadas Ciclovias Cariocas: uma Avaliação à Luz da Legislação Federal e das Recomendações Técnicas. Anais III Simpósio de Pós-Graduação em Engenharia Urbana - SIMPGEU, 2012, Maringá, PR. 